\title{
Stakeholder Perceptions and Experiences of a College Live Mascot Program: a Study of Higher Education Ad Hoc Change
}

\author{
Clinton A. Patterson ${ }^{1}$ (D) Don M. Beach ${ }^{2}$ (D) $\cdot$ Juanita M. Reyes $^{3} \cdot$ Stephen M. Sloan $^{4}$
}

Accepted: 3 February 2021 / Published online: 10 March 2021

(C) The Author(s), under exclusive licence to Springer Nature B.V. part of Springer Nature 2021

\begin{abstract}
Organizational change is a complex and critical issue in higher education today. Changes experienced across institutional systems have both short-term and long-term impact, making this phenomenon ripe for educational leadership research. Many universities and colleges have applied Kotter's (1995) eight-step change model prescriptively to implement academic initiatives, curriculum revisions, and strategic vision. However, Kotter's (1995) model has not previously explored ad hoc changes over time and has not been used to study a college live mascot program. Although a decreasing campus tradition, college live mascots have a relationship and impact on a student's experience and college identification, as well as university engagement with alumni and the public. Therefore, understanding how change is identified and experienced by campus stakeholders of a college live mascot program describe the various complexities and issues that initiate a climate for institutional change. To explain the evolution of a college live

Clint Patterson currently works in the Center for Texas Excellence at Texas A\&M University where his current projects focus on the transformative doctoral education model, mentorship initiatives, and interdisciplinarity. Previously, he worked at Baylor University in the Division of Student Life and with the Bear Program. This particular work is an extension of his 2018 Educational Leadership dissertation with Tarleton State University.

Don M. Beach is a Professor in the Educational Leadership and Technology Department at Tarleton State University. He has received numerous teaching and educator awards, including being named Regents Professor in 2008 by the Texas A\&M University System, and the 2016 Educator of the Year by theTexas Council of Professors and Educational Administration (TCPEA). Dr. Beach has authored or co-authored nine books, 14 book chapters, and over 50 scholary articles.
\end{abstract}

Juanita M. Reyes is an Assistant Professor in the Educational Leadership and Technology Department at Tarleton State University. She earned her doctorate of education in Educational Leadership in 2007. She currently is a faculty leader for educational initiatives at Tarleton's campus in Fort Worth, TX.

Stephen M. Sloan is the Director of the Institute for Oral History and Associate Professor of History at Baylor University. He is a past president of the national Oral History Association. His projects have been funded at the local, state, and national level. He created Waco History, a website and free mobile app on local history. Listening on the Edge: Oral History and Crisis (Mark Cave and Stephen M. Sloan, Eds) won the 2015 Oral History Association Book award.

Clinton A. Patterson

capatterson@tamu.edu

Extended author information available on the last page of the article 
mascot program, oral histories across twenty years of campus stakeholders, including student trainers, campus administrators, and external consultants were analyzed using Kotter's (1995) model. The findings of this study affirmed that the steps associated with Kotter's (1995) change model, with a specific focus on the first three steps, are relevant for ad hoc changes, and offer implications for higher education change.

Keywords Organizational development $\cdot$ Campus tradition $\cdot$ Kotter $\cdot$ Strategic planning $\cdot$ Oral history $\cdot$ Mascot

Institutions of higher education are often seen as resistant to change or tied to tradition. External pressures (e.g., accreditation, cultural and diversity issues) often provide triggers sparking institutional and episodic change within American colleges and universities (Farris et al., 2009; Fumasoli \& Stensaker, 2013; Kang et al., 2020; Stanley et al., 2019; Woods et al., 2017). Influenced by Lewin's (1951) three stages (unfreeze-transition-refreeze), Weick and Quinn (1999) introduced the term episodic as changes "that tend to be infrequent, discontinuous, and intentional...occur in distinct periods during which shifts are precipitated by external events" (p. 365). Prior to the COVID-19 pandemic, intercollegiate athletics arguably experienced some of the most dramatic moments of educational change in response to external pressures. For example, many long-standing rivalries were abruptly discontinued (e.g., Texas A\&M University versus University of Texas; University of Nebraska versus Oklahoma; University of Missouri versus University of Kansas) despite their positive contributions to school identity and community (Bronner, 2012; Havard \& Eddy, 2013). These instances influence organizational decision-making, subsequent personnel changes, and institutional culture (Baranko, 2010; Bronner, 2012; Havard \& Eddy, 2013; Tarver, 2017).

Another campus area deeply ingrained in individual and collective identity, as well as university tradition, is college mascots (Baranko, 2010; Bronner, 2012; Riess, 2015; Tarver, 2017). Collegiate symbols and mascots represent a school's public image or identity and the qualities expected of their intercollegiate teams (Almond, 2020; Bronner, 2012; Riess, 2015). Deeply rooted in intercollegiate athletics, mascots impact institutional identity, campus programming, and federal regulations (Baltz \& Ratnaswamy, 2000; Baranko, 2010; Bronner, 2012; Schultz \& Sheffer, 2018), and often undergo ad hoc and episodic changes. For example, Native American activists began a movement in the late 1960s to remove higher education's promotion of negative stereotypes that were often represented through costume or imagery (Guiliano, Messner, \& Hartmann, 2015; Riess, 2015). By 2001, more than 600 schools and colleges had relinquished their Native American Indian symbols (Riess, 2015). As the Native American mascot controversy illustrated, symbolic depictions and imagery at the collegiate level influence public passion and unrest (Baranko, 2010; Guiliano, Messner, \& Hartmann, 2015; Riess, 2015), and universities often respond by initiating change. Furthermore, colleges with live animal mascots have faced difficult environments and external pressures from the National Collegiate Athletic Association (NCAA), United States Department of Agriculture (USDA), animal activist organizations like People for the Ethical Treatment of Animals (PETA), and public engagement, each of which seems to be calling for this campus tradition to change (Baranko, 2010).

A common framework applied to higher education organizational and episodic change is Kotter's (1995) Change Model. This process-based model includes eight steps envisioned to elicit a single change or initiative through internally-led linear implementation (Kotter, 1995). However, because Kotter's (1995) Model is most often applied prescriptively, many higher 
education studies span short durations. This study will extend current literature and fill existing gaps by utilizing Kotter's (1995) Model as a framework for understanding a twenty-year long episodic change in a college live mascot program. The purpose of this paper, therefore, is to use Kotter's (1995) model as a framework to investigate how a climate for change is created across two decades of episodic and ad hoc changes within a single college live mascot program. While no specific framework was used to drive these changes in real time, we will use the first three steps of Kotter's (1995) Model as an evaluative tool and a lens to analyze the longitudinal change process and offer implications for higher educational organizational change and college mascots.

\section{Kotter's (1995) Eight-Step Model}

Designed as a linear, prescriptive, and process-based framework for strategic change initiatives, the eight steps of Kotter's (1995) Change Model include: 1) sense of urgency, 2) guiding coalition, 3) create vision, 4) communicate vision, 5) empower action, 6) create quick wins, 7) build upon change, and 8) institutionalize change. Kotter's (1995) Framework can also be divided into phases, with the phase one 'creating the climate for change' (steps 1-3), second phase 'engaging and enabling the organization (steps 4-6), and 3) implementing and sustaining for change' (steps 7-8). Specifically, this study examines the first phase and how a climate for change is created through ad hoc change process. As such, we outline those associated three steps of Kotter's (1995) first phase.

Sense of Urgency According to Kotter (2012), "establishing a sense of urgency is crucial to gaining needed cooperation" (p. 37). In this initial step, organizations must evaluate how they currently operate in order to determine if change should occur (Farris et al., 2009; Kang et al., 2020; Nahata et al., 2010; Woods et al., 2017). Organizational stakeholders and leaders must be familiar with current internal and external elements associated with their discipline (Kotter, 2012). Areas of potential change impetus should be well understood, such as political and financial triggers (Kotter, 2014).

Guiding Coalition Kotter (1995) explained how members of a coalition or advocacy group often possess certain tangible and intangible attributes. For example, a member with positional power within the organization can impact the level of success for the change (Kang et al., 2020; Kotter, 1995; Nahata et al., 2010). Additionally, expertise and knowledge are critical for team members to obtain, as well as establishing members' credibility within the organization (Kotter, 2012). Others often view members of a guiding coalition as leaders capable of managing and leading during change (Kotter, 2014).

Create Vision The third step in Kotter's (1995) change model is to develop a vision and strategy. This simple yet powerful step sets the directional course for the guiding coalition and organizational entity (Kotter, 2012; Woods et al., 2017). Clarity in the vision is critical for any change process, as this enables constituent identifiable and discernable outcomes (Kotter, 1995).

Higher education practitioners and researchers have implemented and followed Kotter's (1995) change model to initiate organizational change (Farris et al., 2009; Kang et al., 2020; Nahata et al., 2010; Woods et al., 2017). The majority of Kotter-related literature in higher 
education studied internally-led implementation of all or part of the eight steps as prescribed in a variety of contexts, such as: faculty development (Leugers et al., 2009; Simonson, 2005), curricular reform (Farris et al., 2009; Nahata et al., 2010), and diversity (Stanley et al., 2019; Watts, Cuellar, \& O'Sullivan, 2008). Not until recently have scholars called for additional research and robust theorizing of Kotter's (1995) change model, which is where this study is situated (Appelbaum et al., 2012; Kang et al., 2020; Simonson, 2005).

\section{The Current Study}

Baylor University's first live bear mascot arrived on campus over one-hundred years ago (O'Brien, 1950) and the university remains one of the few institutions of higher education in the United States operating a live mascot program (Baranko, 2010). During the 1930's, a student service organization assumed responsibility of the developing mascot tradition (Baker, 1996; O'Brien, 1950) and maintains that role today. The school has been home to more than fifty mascots since the very first bear arrived on campus (Baker, 1996). The current mascots are biological sisters, American Black Bears, and have only known a life as part of the university (Gibson, 2005). With the acquisition of the current mascots (Joy and Lady) in the early 2000's, the university publicly pledged their commitment to keep the animals their entire lives, rather than adhering to the informal tradition of retiring a bear every few years for another cub. Maintaining a college live mascot program became even more difficult and complex because of the external forces such as animal rights groups and Animal Welfare Act standards, despite the creation of new million-dollar bear habitat in 2005. As a result of the institutional commitment to keep the current animals their entire lives, many of the central elements of this tradition, such as their campus facility, leash walking, and even football game attendance, were reimagined and experienced unprecedented changes.

Specifically, we investigate twenty years (1997-2017) of historical, qualitative data concerning organizational change within the Baylor University's Bear Program. By applying Kotter's (1995) framework retrospectively as a lens to longitudinally understand how a climate for change within a college mascot program was created, this research is distinctive from previous Kotter-related scholarship, and thus, extends the larger discussion of Kotter's (1995) Model. Our research utilizes the first three steps of Kotter's (1995) Change Model as an evaluative tool to understand how atheoretical or ad hoc changes were experienced and perceived. Incorporating Kotter's (1995) Model in this way, we can better understand Kotter's (1995) Model while also identifying emergent points, themes, or patterns which develop during a climate for change.

\section{Methodology}

As the focus of this study examined how a climate for change was experienced within a college live mascot program, oral history interviews by undergraduates, campus administrators, and alumni involved in the mascot program provided a worthy backdrop to analyze stakeholder experiences and perceptions. Overall, fifteen narrators, including current and former student trainers and internal and external stakeholders of the college live mascot program, provided data for the qualitative analysis for the first phase of Kotter's (1995) Change Model through the oral history methodology. Purposeful, convenient, and maximum variation sampling were used to 
Table 1 Narrator's mascot experience and interview status

\begin{tabular}{llll}
\hline Narrator & College Mascot Role & College Mascot Years & Status at Interview \\
\hline Charles & Trainer & $1956-1959$ & Alumni \\
Gordon & Trainer & $1957-1960$ & Alumni \\
Stephen & Trainer & $1958-1962$ & Alumni \\
Alan & Trainer & $1991-1995$ & Alumni, University staff \\
Bryan & Trainer & $1994-1997$ & Alumni \\
Ryan & Trainer & $1999-2002$ & Alumni \\
Adam & Trainer & $2000-2004$ & Alumni \\
Todd & Trainer & $2001-2004$ & Alumni, University student \\
Patrick & Trainer & $2009-2011$ & Alumni \\
Travis & Trainer & $2010-2013$ & University student \\
David & Trainer & $2011-2014$ & University student \\
Martha Lou & Campus administrator & $2009-2019$ & Alumni, University staff \\
Betsy & Student organization advisor & $1996-2018$ & Alumni, University faculty \\
Scott & Professional consultant & $1997-$ present & Professional Consultant \\
Jim & Veterinarian & Professional Veterinarian \\
\hline
\end{tabular}

invite participation in oral history interviews because of their affiliation with this college mascot program (Creswell \& Poth, 2018; Principles and Best Practices of Oral History, 2009). The diversity of the roles and years associated with the college mascot program ensure a varied sampling of experiences and perspectives with this unique campus tradition. The fifteen narrators in this study, including their years associated with the college mascot program and university status at the time of their interview, are depicted in Table 1.

Narratives within this study followed the Oral History Association's General Practices for Oral History (Principles and Best Practices of Oral History, 2009). Interviews were framed as life history, an oral history approach to encourage narrators to describe their lived experiences (Sharpless, 2007). The shared-authority interview process helped monitor research bias (Creswell \& Poth, 2018; "Principles and best practices of oral history," 2009), as Baylor University's Institute of Oral History transcribed the audio file, then the primary researcher reviewed and edited, before the narrator reviewed the transcript. The Institute accepted the responsibility for preservation and security of both audio and transcript files. ("Principles and best practices of oral history", 2009).

In order to understand Bear Program stakeholder experiences, perceptions, and application of concepts associated with the first three steps of Kotter's (1995) Change Model, research questions were applied to the previously collected transcripts and analyzed through Kotter's (1995) Framework. Specifically, Kotter's (1995) first three steps, sense of urgency, guiding coalition, and create vision were used as a framework for extracting, coding, and analyzing data using open and axial coding techniques (Corbin \& Strauss, 2015; Creswell \& Poth, 2018). Oral history narrator analyses are reported "without much comment" (Shopes, 2015, p. 307).

\section{Findings}

Two main climates for change quickly emerged in the qualitative findings that describe a sequence of ad hoc and episodic changes over twenty years of the Bear Program. Themes (see Table 2) relating to each climate and the first three steps in Kotter's (1995) change model are supplemented with narrator data. 
Table 2 Themes related to change climates

\begin{tabular}{|c|c|c|}
\hline Kotter step & First change climate & Second change climate \\
\hline Sense of urgency & $\begin{array}{l}\text { External pressure, specifically } \\
\text { from animal activists; outdated } \\
\text { bear facility; safety concerns }\end{array}$ & $\begin{array}{l}\text { External pressure, specifically from USDA; } \\
\text { lean student trainer involvement; safety concerns }\end{array}$ \\
\hline Guiding coalition & $\begin{array}{l}\text { Student-centric with external } \\
\text { stakeholders; little university } \\
\text { involvement }\end{array}$ & $\begin{array}{l}\text { Student-centric with external stakeholders; } \\
\text { increasing university involvement }\end{array}$ \\
\hline Create vision & $\begin{array}{l}\text { Keep Joy and Lady their entire lives; } \\
\text { new bear habitat }\end{array}$ & $\begin{array}{l}\text { Remove leash walking tradition; expand } \\
\text { on-campus collaborations }\end{array}$ \\
\hline
\end{tabular}

\section{First Climate for Change}

Occurring near the start of the studied timeframe, the first climate for change was initiated by external pressures from animal activists, along with safety and welfare concerns, before ultimately prompting the university decision to keep two live bear mascots for the entirety of their lives.

Sense of Urgency In the early 2000's, the Bear Program experienced unprecedented and powerful external pressure from animal activists. Specifically, video footage of a festive student scene with loud music at the bear facility was circulated by an animal activist organization and forecasted a climate pressing for change. Bear Committee member Todd remembered the "protesting at the bear pit on campus... and [the video] got publicized. So we had to deal with that." Appalled at the student behavior, Veterinarian Jim learned of the event after the video "exploded on the internet, [but] I would have talked to somebody and said, 'this is ridiculous. You cannot do this." Todd further recalled the Bear Program feared extreme or "too militant" behavior from animal activists and "one of the bear trainers had to sleep with the bears overnight because we heard word that they were going to throw poisoned fish over the fence to kill the bears." According to Jim, animal activists were not the only external concerns because there was "really a manifestation of what was going on between the USDA...federal regulations for animals kept in captivity and also the American Zoo Association."

At this time in the Bear Program, the mascot on-campus exhibit was an all-concrete pit built in 1976. According to student trainer Adam, "the [previous bear pit facility] was a good habitat at first, but it really didn't meet the standards of today's zoological exhibits that really Baylor represents." Scott believed "after seeing the effects of the life on concrete and its toll on animals, that was the beginning of the discussion of updating and renovating the bear-going from the bear pit and turning it into a bear habitat that's much more animal friendly." Veterinarian Jim further expressed a need for an updated facility "because outside of the [university] family, it was antiquated, and it was well beyond its time as an exhibit.....and 'we've got to do something about this falling down grotto that's not a good representation."'

As bear facility concerns were emerging, so too were safety and risk concerns in the student trainer's interaction with bears. For example, when Scott arrived on campus in 1997 as the professional consultant, he recalled being "very surprised that there wasn't at least one fatality, if not many, working around bears and not having any proper safety equipment. The place was running a little loose." Student trainer Bryan commented on the lack of standard operating procedures, stating, "we didn't have official processes or things like that." 
Narrators emphasized in great detail the pressuring animal activists' efforts and "whether they are right or wrong, they're vocal and bring a lot of attention." The internal leaders who worked to create a sense of urgency were the bear trainers and the Bear Program's veterinarian and professional consultant. These types of developing concerns focused on the outdated bear facility and student safety around the animals.

Guiding Coalition Following the described senses of urgency, the student-centric guiding coalition consisted of student trainers, student organization adviser, and two external stakeholders (veterinarian and professional consultant), with the university leadership slightly increasing their presence. Although influential in creating a sense of urgency for the Bear Program, animal activists and USDA were not represented within this guiding coalition.

At the beginning of the episodic change period studied, the internal leaders of the Bear Program consisted of only the student trainers and the student organization's advisor. Bear trainer Adam reflected on the Bear Program's uniqueness and specialized work because "there was nobody they could really go to outside of the small circle... we had...Bear Committee, bear trainers, and you know, our vet, USDA, Texas Parks \& Wildlife, and our bear [professional consultant]." But, Adam remembered how the sense of urgency themes led to "spend[ing] a lot of time with...the vice president of Student Life, and...the vice president of university life, and...the chief of staff to the president at the time, and [the university president] himself." However, university employees were generally not involved in the Bear Program, as the student organization's adviser Betsy often "had more of a direct involvement and met with [the professional consultant] every time he came to campus, was there when they had the [USDA] inspections - different things like that." Then in 1997, Bear Program student trainers recruited external perspectives through a professional consultant and veterinarian, which Bear Program campus stakeholder Martha Lou described as "we've been blessed by having expertise from a number of different sources." Professional Consultant Scott approached his involvement "to see, make sure that the students were being safe, that the bears were happy and healthy, and that the program was moving in a good, well-though-out manner."

Create Vision During the first change climate, the Bear Program created a central vision to keep two bear mascots their entire lives. Scott described how this vision deviated from the Bear Program's practice that "most of the bears they [Baylor] would keep until about two years old. So they [the bear] would stay through a class [student trainer] and then rotate it out." Adam remembered being "in quite a few meetings about the next step and the best way to facilitate making sure that the bears got what they needed." Following the retirement of an aging male bear in 2001 and another male bear in 2002, this central vision was further developed by acquiring "two female bear cubs, one year apart." Ryan recalled "And so the decision was made, 'Let's take Billy [the retiring bear] out to Scott's ranch, we'll retire him. Scott will go up to Oregon, get the new bear [Joy], bring her to his ranch and we'll essentially trade bears." Scott recounted that "so far it's proven itself out to be a good match for the bears and for the university."

With the cubs "stirring more excitement in the program", the Bear Program constructed a new million-dollar bear habitat (with natural substrate) (Gibson, 2005). Martha Lou remembered how student trainers "had the personality of selling the idea" and initiated the dream. In an example of multi-faceted stakeholder support and vision, mascot namesake and former Baylor University first lady Joy recalled how the student trainers "did not have financial help with some of the things that you needed to do to take care of the bear." Joy was motivated to 
donate to the new habitat and program after learning the university development office expected "each [Bear Program student] member had to first give a hundred dollars. That was unreasonable to me because [the student leaders were] giving so much time and I didn't like their being asked to start by individually giving a hundred dollars."

According to Martha Lou, "it became obvious to us that something needed to be done" to address emerging concerns expressed by external pressures and maintain healthy bears. The decision to keep Joy and Lady their entire lives created new vision for the Bear Program, including building a new facility, and shaped emerging changes.

\section{Second Climate for Change}

Nearly a decade later, a second climate for change was created when external pressures again influenced the university's decision to deviate from the long-standing tradition of walking the bears on leash in public and bringing the mascots to football games.

Sense of Urgency Small ad hoc changes related to the care needed for two growing adult bears climaxed when the long-standing tradition of walking the bears on leash, including on campus or at football games, was ultimately discontinued due to external pressure. Martha Lou, now the campus administrator for the Bear Program, described how the accrediting organization, "was already pushing for no more walking. A lot of those early conversations with...the [USDA] inspector, were around the fact that that was highly risky." According to bear trainer Patrick, this area of increasing concern for USDA peaked when the Bear Program's license for renewal "somehow got shelved or somehow it fell through the cracks, and our license ended up expiring." Additionally, Martha Lou described how, "they [USDA] really had us in a bind because they didn't want walking. We had always done walking and had planned to continue walking, but we weren't going to get our license back until we agreed not to walk any longer."

At the same time, two internal situations were subtly emerging simultaneous to USDA increasing external pressure. First, Patrick described an overall desire shared with the professional consultant to "eliminate some of the risk... and we felt as a program - that was about 90 percent of our risk of something going wrong." Secondly, Betsy remembered "lean" years of student trainer recruitment and selection because "we were maybe not really wise about the committee membership there for a while."

In summation, these three situations created a second sense of urgency for internal leaders of the Bear Program. Similar to the first change climate, external pressure was applied (in this case USDA and not animal activists). The Bear Program's lost exhibitor license led to a tipping point encounter in the near 100-year tradition of walking the mascots on leash. Plus, the external perspectives of the internal coalition advocated for improving safety practices to reduce risk and elevate the quality of animal care.

Guiding Coalition After increasing external pressure from USDA for safety concerns and a lost exhibitor's license, the once informal and student trainer-centric Bear Program evolved into more formal and institutional structures. According to Martha Lou, "at that point, USDA wasn't as willing to take a student group's worked for certain things. They wanted it to be a university commitment." Martha Lou described such university commitment of the Bear Program through "the approval and support that [vice president for university operations] 
got from [university CFO], [vice president of Student Life] really continuing to say, 'this is our mascot. This is high visibility. It's [The bear habitat is] one of the most visited sites on campus. Our bears need to be healthy. We can't do some of what we want to do. Let's look at alternatives of what we still absolutely need to do." Although many of the animals' student caretakers were "disappointed" with no longer walking the bears, Patrick "remember[s] having discussions with various [university] administrators and kind of the theme of those discussions was the...need to go forward as a program." Patrick even reflected "at that point we had to decide... as a program, what we were going to do. And we had a lot of things that we had to work through, and we ended up making a lot of foundational changes." In addition to ending the leash walking tradition, Patrick described how the often hierarchical "leadership structure changed to a Lead Team.... and instead of being a trainer and a coordinator, it was now three trainers who all had separate responsibilities."

Create Vision The decision to no longer walk the animals on leash offered new opportunities for the Bear Program to create safe practices and expand campus partnerships. Specifically, this safety initiative required student trainers to update standard operating procedures and "completely revamp everything that we did as a program. And that was really technical work ... [it was] very important; it had to be done but it was not fun...starting from the ground and working our way up." Baylor's School of Computer Science and Engineering created a "new system" to support a no-contact operation at the habitat and transportation of the bears that bear trainer David described as "safer for us, it's more comfortable for the animal." This partnership also redesigned the habitat's docking system and that of the transport trailer to eliminate "needing to have a leash on the bear and kind of having any of that direct contact in order to transfer the bears from one facility to another." The university's commitment to this safety vision was further exemplified through the financial investment of creating a secondary enrichment facility for the bears that according to a David, "is much more conducive to what we want to do and it's a much, I think, better environment. .. it gives them [bears] a chance to kind of get out of that normal habitat and explore... and, as we say, just be bears."

Another example of the Bear Program refining vision was through partnership with Baylor's School of Education to enhance the program's educational outreach efforts. According to bear trainer David, the student trainers "knew the information, but we brought in the education folks that really knew how to... make it real and make it really powerful to an audience." Student trainer David recalled having the "idea to make it a more standard curriculum" and achieve compatibility with the state's educational learning outcomes. Martha Lou again acknowledged value in the Bear Program's multi-faceted support and vision because, “...number one, it's great for...the students with the public and teaching and giving those presentations. Number two, it helps, I think, validate our position that we are a Class C zoo and - providing education for the public."

The discontinuation of walking the bears on leash influenced the internal leaders to create a second vision of episodic change. Here, the Bear Program experienced valuable campus support through new partnerships with the university's academic experts that facilitated safe operations and innovative educational approaches.

\section{Discussion}

Overall, our interpretation of these findings discovered Bear Program stakeholders experienced ad hoc change in ways congruent with Kotter's (1995) process-based framework. Our analysis 
revealed important themes that fill gaps and has implications for future research regarding organizational change, as well as the study of college mascots. Based on our analyses of the first three steps in Kotter's (1995) Framework, we learned ad hoc change generates an adaptive system and mascots facilitate emotional connection.

\section{Change Is an Adaptive System}

Ad hoc changes create an adaptive system where guiding coalitions evolve, (re)vision is created, changes emerge non-linearly, and true urgency is formed. Guiding coalitions and their organizations should be strong yet nimble enough to appropriately adapt to climates creating change. The Bear Program experienced almost an organic multi-faceted approach through Joy's action in lieu of the student trainer donations requirement, and later through the academic partnerships forged to implement safety changes and improve the educational mission. Also in the second climate of change, student trainers like Travis demonstrated adaptive resilience when "the direction that the program took...definitely more than made up for missing out [on walking the bears at football games]." However, the deep symbolism often associated with college mascots and traditions may be difficult to navigate. For example, the financial support and donor affinity may or may not align with the vision of the internal stakeholders. Guiding coalitions should be in tune with organizational and institutional goals, and strategic planning is paramount. This is often difficult for student-focused organizations that may or may not have inclusion at the vision table, thus high-levels of intergroup collaboration are vital to ensure a successful program. Administrators may wish to follow Betsy's advice "the more people you have involved with it, the more people that buy into it and have ownership in it. That's just good for the university." Therefore, we conclude change, in particular ad hoc and episodic change, requires a high-level of stakeholder persistence and multi-faceted involvement.

Another intriguing finding with previous Kotter-related literature of prescriptive implementation was an evolution of the Bear Program's guiding coalition. In the early portions of the episodic changes, student trainers and their recruited consultant and veterinarian operated adjacent but largely separate from university infrastructure. In fact, it was not until the animals became larger and stronger, significantly elevating the Bear Program's risk level, that the university established a formal team. For example, Betsy recalled "slight federal oversight" when she began the student organization advisor role in 1997 but overtime "the university has been more supportive of the Bear Program financially...really different from how-we pretty much used to just kind of operate on our won, and now we-it's different now."

Several factors could impact why the guiding coalition evolved later into the change period. These narrators described change implementation on an ad hoc basis, but we would suspect a team would likely have been formed earlier if Kotter's (1995) Model was implemented as a linear process (Farris et al., 2009). Second, the Bear Program is heavily operated by students and thus experiences high-volumes of student turnover through matriculation. Similarly, administrators may come and go. To mitigate student and administrative turnover, the Bear Program (and other campus programs undergoing change), should seek to maintain continuity among the guiding coalition and if that is not the case, ensure continuity of the changes through succession planning.

Linear implementation of Kotter's (1995) Framework certainly offers one effective way for higher education to create vision. However, our research indicates episodic or ad hoc change creates more than one vision, or rather (re)visions. The Bear Program created (re)vision when 
the mascot leash-walking was discontinued. Student trainer Patrick articulated this watershed moment as "we'd never been here as a program before, because I think it was in 2000 or 2001, when we first got these bears, Baylor University had made a commitment that we were going to keep the bears for their whole natural life. It's the first time that we'd ever done this." Although this tradition appealed to fans, spectators, and student trainers, no more leash walking the bears also meant no longer attending football games. And former trainers had difficulty accepting this change in tradition, even with the known risk, because Stephen encouraged Baylor to "think seriously about, for 2017 [centennial anniversary of bears on campus], bringing the bear at least to one game just on a trial basis and see how it's received and see what happens." This statement illustrates a reality that not everyone may like the vision (or how subsequent changes are implemented). Creating (re)vision is often iterative and enables input from constituents, which should not only inform the vision but also identify other areas of Kotter's (1995) Model such as points of urgency and small wins.

Another discovery is how the emergent changes interacted with the rigid process-based intent of Kotter's (1995) Model. Our findings reveal change is often addressed organically and non-linearly, and in many cases actually appear continual, iterative, or cyclical (Farris et al., 2009; Kang et al., 2020; Nahata et al., 2010). For example, a sense of urgency occurred at multiple points over the twenty-year period and led to keeping Joy and Lady their entire lives, a new bear habitat with improved animal care and safety operations, and the transition to no longer walking the animals on leash. These emergent and complex changes prompted organizational change through increased institutional oversight and campus collaborations, suggesting ad hoc change is evolving and iterative (Kang et al., 2020). Recent iterative implementation using Kotter's (1995) model recommends pairing the prescribed framework with appreciative inquiry (Drew \& Wallis, 2014). Similarly, we recommend ad hoc change implementation could pair Kotter's (1995) Framework with design-based research (Kang et al., 2020). In order to better understand change, regardless if prescriptively implemented or not, we recommend open-ended interview questions rather than rigid questions specific to Kotter's (1995) eight steps. Additionally, oral history, and specifically the life history approach, offered a non-prescriptive means to study these changes within the lived experiences of Bear Program participants (Portelli, 1981; Sharpless, 2007).

Recently, Kotter and Cohen (2008) claims establishing a sense of true urgency is the most critical of the eight steps in the model and organizations should strive to "behave with true urgency themselves every single day" and not "just say the right words daily." Narrative analysis indicates a sense of urgency occurred in the Bear Program because of the actions and decisions of internal leaders (i.e., bear habitat, no more walking on leash). To be fair, safely maintaining a program with as high-level of risk as the Bear Program is of utmost importance and should regularly experience urgency because "we always run the risk if something goes wrong, they'd splash it all over the news." Risk accompanies every action and decision for many higher education organizations, but especially for college live mascot programs (Baranko, 2010). These findings indicate risk awareness, regardless if internally or externally created, contributes to a sense of urgency. Because Kotter predicts that true urgency we encourage internal leaders to be in tune with the external constituents and pressures.

\section{Mascots Foster Emotional Connections}

While we agree with Kotter and Cohen's (2008) recommendation that internal leaders appeal to their constituent's hearts to evoke feelings that encourage moving change forward, our mascot research 
shows external pressures also lead change. According to Betsy, the habitat elicited emotional connections because "... more people contributed to the construction of the habitat than any other program in [Baylor]...people love the bears... and over the years, alums who had had special memories in the bear habitat and the Bear Program, so it was very well supported." Therefore, these narratives indicate ways college live mascots can be utilized as a positive marketing communication tool with higher education constituents (Wandel, 2017). The art of emotional branding through anthropomorphism, or mascot storytelling, can foster engagement and connection (Bronner, 2012; Schultz \& Sheffer, 2018; Wandel, 2017). Anthropomorphism occurs when an animal, such as a college live mascot, possesses human behavior or the ability to talk. College athletic administrators recently recognized anthropomorphism lessens a spectator age gap and their school's mascot appeals to young audiences, who will eventually become ticket holders. For example, fans and animal lovers alike were able to share in the emotional experience of Mike IV, the beloved tiger mascot at Louisiana State University, when he was diagnosed with cancer in May 2016 before dying in October 2016. The University of Texas' Bevo mascot and other schools' mascots (including the case study) sent Mike IV flowers and notes, demonstrating a special bond between live mascots, caretakers, and fans (Wandel, 2017). LSU administrators described a belief "that it's very important to view Mike as a brand ambassador to not only the Athletic Department but also the University" (Wandel, 2017, p. 183). However, anthropomorphism also brings danger to these programs, and could create complacency by blinding administrators and animal trainers from the potential dangers or risk.

Data analysis revealed the Bear Program encountered two moments of urgency were strongly influenced (if not instigated) by powerful external pressure. In the first change climate, although student trainers began dreaming and subtly advocating for a new bear habitat as early as 1997, Adam hypothesized the negative and vocal publicity from animal activists "really sparked a conversation within [the university] and allowed us to proceed, probably a little bit more expeditiously with building the new habitat, that gave the bears really what they deserve." Similarly, veterinarian Jim speculated the "[animal activists] and their abrasive nature made Baylor University say, 'Okay, we're not getting rid of our bears, but here's what we're going to do."' Contrarily, our research suggests external pressures are regularly present within and across organizations associated with episodic change. Although never a part of the formal guiding coalition, animal activists and USDA notably influenced the direction of the Bear Program.

Lastly, the Bear Program depicts a distinct dichotomy of identity that arises when longstanding campus traditions face legal, safety, and cultural concerns (Baranko, 2010; Bronner, 2012; Schultz \& Sheffer, 2018). By striving to become more inclusive in their community, colleges and universities may initiate changes to their institutional identity after re-evaluating their campus traditions. Notable examples within recent months include the University of Virginia changing their school logo, the University of Florida discontinuing their "Gator Bait" cheer, and activists calling for the University of Texas to remove their school song. This research provides valuable insights and directions that connect students and stakeholders to the lifeblood of the university through campus initiatives rich with institutional traditions (Almond, 2020; Bronner, 2012).

\section{Limitations}

While an effort to include a vast and representative sample of narrators was made, additional oral history collection could more fully present a historical and holistic view across the Bear 
Program's one hundred- and three-year history. For example, increasing the number of campus administrators interviewed would create a deeper account of how administrators perceive, consider, and respond to changes in higher education. Additional current and former student trainer interviews would create an even richer and more robust description of change over the program's history.

Though not necessarily a limitation but rather an acknowledgement, a student trainer and campus stakeholder were roles assumed by the primary researcher during this change to provide care for the bears their entire lives. This case study remained an investigation into the experiences and perceptions of participating stakeholders of a college live mascot program and was neither a collection nor analysis of the primary researcher's involvement. The primary researcher was committed to allowing the oral histories and analysis to express stakeholder involvement and perspectives, free from misguided researcher bias and interpretation.

\section{Future Research}

The majority of previous Kotter studies occurred over a short-timeframe and the participants implemented the framework as the linear stages are prescribed (Nahata et al., 2010; Appelbaum et al., 2012). Implementing all eight stages takes time and too often institutions or programs implement and publish before change is institutionalized. Interestingly, because this longitudinal case study covered two decades, future analysis could inform a research gap by presenting insight across the final five principles of Kotter's framework (Appelbaum et al., 2012; Nahata et al., 2010). The narratives presented in the later Kotter's (1995) steps could offer valuable perspectives of how organizations can authentically respond to and experience change. Therefore, we recommend moving forward with future research to explore how the remaining two phases and five steps of Kotter's (1995) framework are analyzed across the twenty-year period of ad hoc changes within the Baylor Bear Program.

In agreement with previous literature, this research indicated college mascots and their images impact the student experience, school identity, and university engagement (Bronner, 2012; Schultz \& Sheffer, 2018). As such, thematic analysis incorporating other theoretical frameworks like situated learning theory (Lave \& Wenger, 1991) or social identity theory (Tajfel \& Turner, 2001) could provide valuable insight. Cultural-historical activity theory (Foot, 2014) would expand our framing of how the same stakeholders experienced and perceived change. For example, a continued investigation into the variation of qualitative narratives surrounding the perceived value of being able to walk the animals on leash and attend football games could speak into the diversity of meanings and emotions represented by campus traditions. Another investigation could explore how the emergent collaborations with School of Education impacts learning boundaries. Research in these areas is relevant beyond higher education change and offers contribution to the fields of learning sciences, sport studies, or student affairs.

\section{Conclusion}

This research established one way Kotter's (1995) change model can be incorporated within higher education change and research. We demonstrated the utility of Kotter's (1995) framework for analyzing, and understanding, organizational change retrospectively. College administrators identify the need for and ultimately respond to change on every higher education 
campus. Sometimes this is a planned, well thought out and executed change, but following a prescriptive model may not be realistic, given the drivers behind changes. For example, external pressures influenced by the COVID-19 pandemic have placed severe stress on many systems in higher education, creating an unstable environment neither conducive nor realistic for prescriptive change. This is evidenced by the lack of precedence for campus social distancing in the classroom, residence hall communities, and athletic events coupled with the need for an instant plan and response.

Finally, these narratives made more visible the influences, complexities, and outcomes of a college live mascot program. Since mascots are a symbolic entry point into campus life for many constituents, there are countless external and institutional influences. In particular, these external influences can be loud, constant, and demand changes in order to comply with standards (Baranko, 2010). The analysis also presented the complexities of successfully operating and maintaining live mascots on a college campus, serving as a valuable resource, particularly since such research is virtually void to college administrators. Each narrator, regardless if a student trainer or Bear Program stakeholder, described an intrinsic value because of their involvement, which also demonstrates college mascots can foster important connections to campus. Thus, this particular case study of ad hoc higher education change exemplified the belief that college live mascot programs are so much more than a mascot.

Acknowledgements The authors would like to express appreciation to Baylor University's Institute for Oral History for supporting this research. Additionally, we are grateful to the peer-reviewers and are confident their scholarly exchange contributed to this manuscript.

Funding This work was supported by a research fellowship from Baylor University's Institute for Oral History.

\section{Declarations}

Human Subjects Research This study was performed in line with the principles and best practices of oral history, as outlined and adopted by the Oral History Association in October, 2018.

Conflict of Interest The authors have no conflicts of interest to declare that are relevant to the content of this article.

\section{References}

Almond, D. (2020). Everyday characteristics of American college towns: Identification and discussion. Innovative Higher Education, 45(4), 267-284. https://doi.org/10.1007/s/10755-020-09504-y

Appelbaum, S. H., Habashy, S., Malo, J., \& Shafiq, H. (2012). Back to the future: Revisiting Kotter's 1996 change model. Journal of Management Development, 31(8), 764-782. https://doi.org/10.1108/ 02621711211253231

Baker, E. W. (1996). Here come the bears: The story of the Baylor University mascots (1st ed.). Eugene W. Baker.

Baltz, M. E., \& Ratnaswamy, M. J. (2000). Mascot conservation programs: Using college animal mascots to support species conservation efforts. Wildlife Society Bulletin, 28(1), 159-163.

Baranko, J. (2010). Hear me roar: Should universities use live animals as mascots. Marquette Sports Law Review, $21,599-620$.

Bronner, S. J. (2012). Campus traditions: Folklore from the old-time college to the modern mega-university. University Press of Mississippi: Jackson. 
Corbin, J., \& Strauss, A. (2015). Basics of qualitative research: Techniques and procedures for developing grounded theory (4th ed.). SAGE Publications: Thousand Oaks.

Creswell, J. W., \& Poth, C. N. (2018). Qualitative inquiry and research design: Choosing among the five approaches (4th ed.). SAGE Publications.

Drew, S. A. W., \& Wallis, J. L. (2014). The use of appreciative inquiry in the practices of large-scale Organisational change a review and critique: A review and critique. Journal of General Management, 39(4), 3-26. https://doi.org/10.1177/030630701403900402

Farris, K. B., Demb, A., Janke, K. K., Kelley, K., \& Scott, S. A. (2009). Assessment to transform competencybased curricula. American Journal of Pharmaceutical Education, 73(8), 1-14.

Foot, K. A. (2014). Cultural-historical activity theory: Exploring a theory to inform practice and research. Journal of Human Behavior in the Social Environment, 24(3), 329-347. https://doi.org/10.1080/10911359. 2013.831011

Fumasoli, T., \& Stensaker, B. (2013). Organizational studies in higher education: A reflection on historical themes and prospective trends. Higher Education Policy; Basingstoke, 26(4), 479-496. https://doi.org/10. 1057/hep.2013.25

Gibson, E. (2005). Bear habitat dedicated during homecoming celebration. Baylor University Lariat: Waco. https:/www.baylor.edu/mediacommunications/news.php?action=story\&story=37631. Accessed 6 Jun 2020.

Guiliano, J., Messner, M., Hartmann, D. (2015). Indian spectacle: College mascots and the anxiety of modern America. Rutgers University Press: New Brunswick.

Havard, C. T., \& Eddy, T. (2013). Qualitative assessment of rivalry and conference realignment in intercollegiate athletics. Journal of Issues in Intercollegiate Athletics, 6, 216-235.

Kang, S. P., Chen, Y., Svihla, V., Gallup, A., Ferris, K., \& Datye, A. K. (2020). Guiding change in higher education: An emergent, iterative application of Kotter's change model. Studies in Higher Education. https:// doi.org/10.1080/03075079.2020.1741540

Kotter. (1995). Leading change: Why transformation efforts fail. Harvard Business Review, 73(2), 59-68.

Kotter. (2012). Leading change. Harvard Business Review Press: Boston.

Kotter. (2014). Accelerate: Building strategic agility for a faster-moving world. Harvard Business Review Press: Boston.

Kotter, J., \& Cohen, D. S. (2008). The heart of change. NHRD Network Journal. 2(3), 175-176. https://doi.org/ $10.1177 / 0974173920080332$

Lave, J. \& Wenger, E. (1991). Situated learning: Legitimate peripheral participation. Cambridge University Press.

Leugers, R., Whalen, T., Couch, S., King, E., \& Prendeville, J. (2009). Re-framing reappointment, promotion, and tenure documents to facilitate the transformation of service-learning pedagogy to community-engaged scholarship. Metropolitan Universities, 20(2), 104-118.

Lewin, K. (1951). Field theory of social science: Selected theoretical papers. Harper \& Brothers: New York. https://doi.org/10.1177/000271625127600135

Nahata, M., Kelley, K., McAuley, J., Bennett, M., Carenes, C., Casper, K., \& Massaro, A. (2010). Renewing vision and strategic priorities for an academic unit. American Journal of Pharmaceutical Education, 74(1), $1-7$.

O’Brien, E. F. (1950). The Baylor bear mascots. Baylor University Chamber of Commerce: Waco.

Portelli, A. (1981). The peculiarities of oral history. History Workshop Journal, 12(1), 96-107.

Principles and best practices of oral history. (2009). Oral History Association. http://www.oralhistory.org/about/ principles-and-practices/. Accessed 6 Jun 2020.

Riess, S. A. (2015). Sports in America from colonial times to the twenty-first century: An encyclopedia. Routledge: New York.

Schultz, B., \& Sheffer, M. L. (2018). The mascot that wouldn't die: A case study of fan identification and mascot loyalty. Journal of Sport in Society, 21(3), 482-496.

Sharpless, R. (2007). The history of oral history. In Charlton, T.L., Myers L.E., \& Sharpless, R. (Eds), History of oral history: Foundations and methodology (pp. 9-32). AltaMira Press: New York.

Shopes, L. (2015). After the interview ends: Moving oral history out of the archives and into publication. Oral History Review, 42(2), 300-310.

Simonson, M. (2005). Distance education: Eight steps for transforming an organization. Quarterly Review of Distance Education, 6(2), 87.

Stanley, C. A., Watson, K. L., Reyes, J. M., \& Varela, K. S. (2019). Organizational change and the chief diversity officer: A case of institutionalizing a diversity plan. Journal of Diversity in Higher Education, 12(3), 255265. https://doi.org/10.1037/dhe0000099

Tajfel, H., \& Turner, J. (2001). An integrative theory of inter-group conflict. In Hogg, M.A. \& Abrams, D. (Eds), Key readings in social psychology. Intergroup relations: Essential readings, pp. 94-109. Psychology Press. 
Tarver, E. (2017). The I in team: Sports fandom and the reproduction of identity. University of Chicago Press: Chicago.

Wandel, T. L. (2017). Brand anthropomorphism: Collegiate mascots and social media. In Information Resources Management Association (Ed), Sports media, marketing, and management: Breakthroughs in research and practice. (pp. 39-61). IGI Global. https://doi.org/10.4018/978-1-5225-5475-2.ch003

Watts, R. J., Cuellar, N. G., \& O’Sullivan, A. L. (2008). Developing a blueprint for cultural competence education at Penn. Journal of Professional Nursing, 24(3), 136-142. https://doi.org/10.1016/j.profnurs. 2008.01.002

Weick, K. E., \& Quinn, R. E. (1999). Organizational change and development. Annual Review of Psychology, 50(1), 361-386. https://doi.org/10.1146/annurev.psych.50.1.361

Woods, C. S., Richard, K., Park, T., Tandberg, D., Hu, S., \& Jones, T. B. (2017). Academic advising, remedial courses, and legislative mandates: An exploration of academic advising in Florida community colleges with optional developmental education. Innovative Higher Education, 42(4), 289-303. https://doi.org/10.1007/ s10755-016-9385-4

Publisher's Note Springer Nature remains neutral with regard to jurisdictional claims in published maps and institutional affiliations.

\section{Affiliations}

\section{Clinton A. Patterson ${ }^{1}$ - Don M. Beach ${ }^{2}$ - Juanita M. Reyes ${ }^{3} \cdot$ Stephen M. Sloan $^{4}$}

1 Center for Teaching Excellence, Texas A\&M University, College Station, TX, USA

2 Department of Educational Leadership and Technology, Tarleton State University, Stephenville, TX, USA

3 Department of Educational Leadership and Technology, Tarleton State University, Fort Worth, TX, USA

4 Institute for Oral History, Baylor University, Waco, TX, USA 